\title{
Frozen motion of gliding bacteria outlines inherent features of the motility apparatus
}

\author{
H. Lünsdorf ${ }^{1}$ and H. U. Schairer ${ }^{2}$ \\ Author for correspondence: H. Lünsdorf. Tel: +49531 6181495. Fax: +495316181411. \\ e-mail: Lunsdorf@gbf.de
}

\begin{abstract}
1 Gesellschaft für Biotechnologische Forschung $\mathrm{mbH}$, Bereich Mikrobiologie, Mascheroder Weg 1, D-38124 Braunschweig, Germany

2 Zentrum für Molekulare Biologie der Universität Heidelberg, Im Neuenheimer Feld 282, D-69120 Heidelberg, Germany
\end{abstract}

\begin{abstract}
High-resolution data of actively gliding wild-type bacteria of four different species and of four different gliding mutants of Myxococcus xanthus were obtained from scanning electron micrographs. By shock freezing and freeze drying, motility-associated surface patterns could be fixed and consequently distinct intermediate states of motion could be observed for the first time. It is shown that these topographic patterns are immediately lost when gliding motility is stopped by blocking the respiratory chain with potassium cyanide or sodium azide. From the surface topography, the mode of action of the gliding apparatus of all four bacterial species examined can be described as a twisted circularly closed 'band'. During gliding, groups of nodes of the supertwisted apparatus show evidence of travelling like waves along the trichomes. However, the spacing between the nodes is not constant but varies within a certain range. This indicates that they are flexibly modulated as a consequence of the gliding state of the individual trichome.
\end{abstract}

Keywords: gliding motility, myxobacteria, frozen motion

\section{INTRODUCTION}

Gliding motility is a mode of translocation of Gramnegative bacteria found in seven of 10 phylogenetic groups (Stackebrandt, 1985) and is described as the ability to move along a solid substratum without the aid of appendices when observed with the light microscope. In addition to flagellum-based bacterial motility, gliding motility appears to be a further form of bacterial translocation. Gliding motility in Myxococcus xanthus is under the regime of two different sets of genes, i.e. one set for S- or social gliding, which is related to the presence of pili, and one set for A- or adventurous gliding of individual cells (Hodgkin \& Kaiser, 1979a, b). The macromolecular mechanism of this kind of cellular movement is still enigmatic. Several models have been proposed which offer diverse mechanomacromolecular and physico-chemical solutions of how bacterial gliding motility is established (Burchard, 1981, 1984; Castenholz, 1982; Pate, 1988; Dworkin, 1996; Spormann, 1999). From the literature, it can be learned that gliding motility is a rather complex phenomenon, based on and influenced by an intrinsic apparatus responsible for mechanical work (Burchard et al., 1977; Pate \& Chang, 1979; Lünsdorf \& Reichenbach, 1989), motility-supporting extracellular slime (Humphrey et al., 1979; Sutherland \& Thomson, 1975; Sutherland, 1979; Gorski et al., 1993), components of the outer membrane (Gorski et al., 1992; Abbanat et al., 1986) and surface active compounds (Keller et al., 1983).

The present study describes surface features of actively gliding versus non-gliding cells from the fruiting gliding bacteria M. xanthus and Stigmatella aurantiaca and the non-fruiting gliding bacteria Flexibacter filiformis and Flavobacterium johnsoniae (formerly Cytophaga johnsonae), supplemented by studies on gliding motility mutants of M. xanthus. For the first time, the "in toto' structure of the motility apparatus and its plasticity, revealed from the gliding-motility-associated cell topography, could be observed at high resolution. This process of cellular translocation is based on a rather dynamic helical superstructure, built as a circularly closed continuum.

\section{METHODS}

Bacterial growth and sample preparation. For 'in vivo' studies of actively gliding cells, four different bacterial strains were used: the fruiting bacteria M. xanthus [strain DK1622, a non-gliding $m g l$ mutant of $M$. xanthus; strain DK6204 (genotype $\Delta m g l A B$; Hartzell \& Kaiser, 1991); and mutant strains DK10407 $\left(\mathrm{A}^{+} \mathrm{S}^{-}\right.$; genotype pilA:: $\left.\mathrm{Tc}^{\mathrm{R}}\right)$, DK11303 $\left(\mathrm{A}^{-} \mathrm{S}^{+}\right.$; genotype $\left.\operatorname{aglB1}\right)$ and DK11316 $\left(\mathrm{A}^{-} \mathrm{S}^{-}\right.$; genotype pilA : : $\left.\mathrm{Tc}^{\mathrm{R}}, \Delta c g l B\right) ;$ M. xanthus mutant genotypes according to D. Kaiser, personal communication] and $S$. aurantiaca (strain DW4/3-1; Qualls et al., 1978), and the non-fruiting 

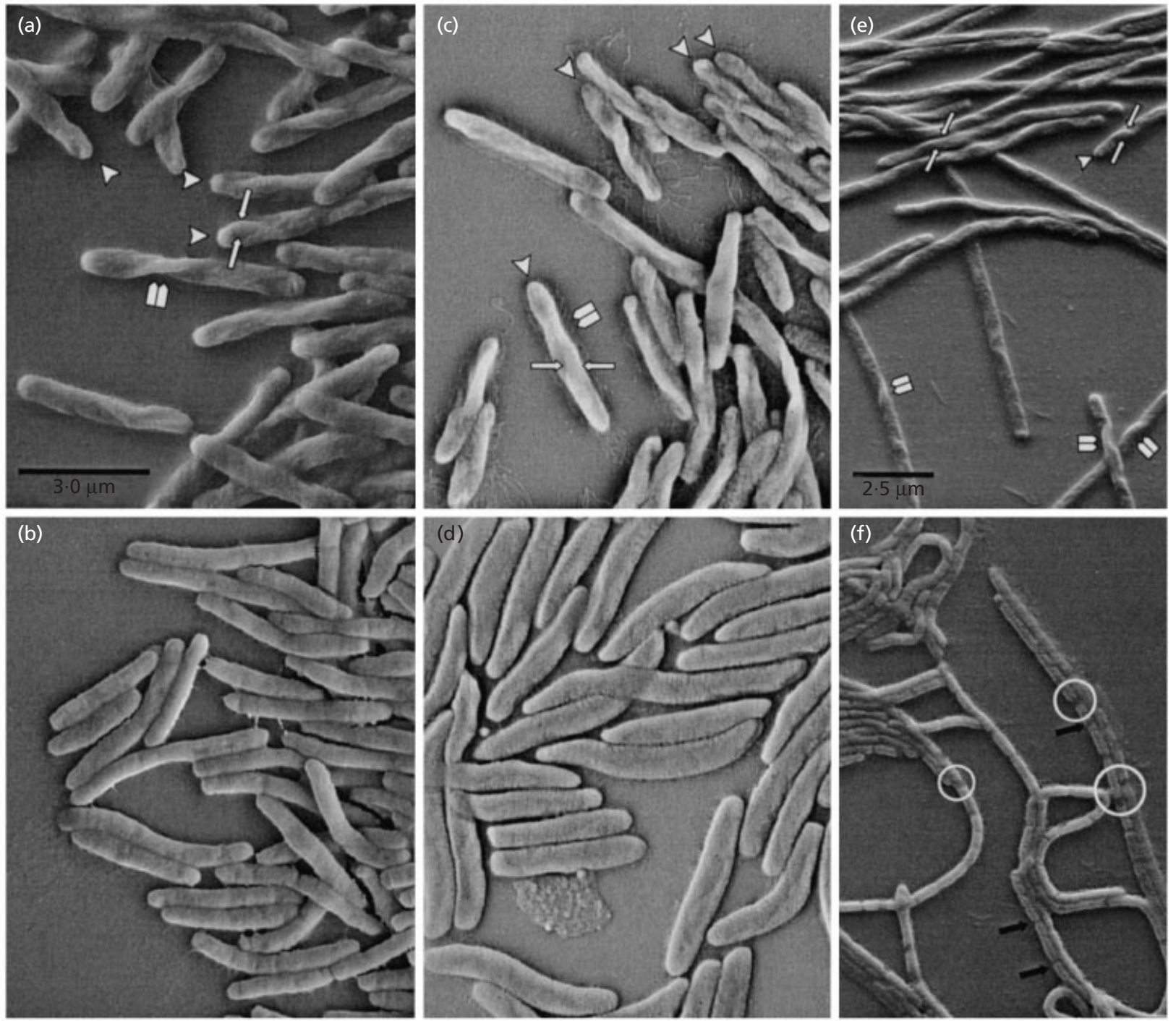

Fig. 1. Views of the gliding state versus the non-gliding state of fruiting and non-fruiting bacteria. (a) $M$. xanthus gliding cells show surface features of a helical 'band' that runs around the cell pole (arrowheads); opposing arrows indicate the 'band' width and double arrows point to the node of the helically wound circularly closed 'band'. (b) M. xanthus cells which have been treated with $80 \mathrm{mM}$ sodium azide. The cells appear smooth and rod-like, but no helical surface features can be recognized. (c) S. aurantiaca gliding cells show helical surface features, which cannot be seen in cells treated with $1 \mathrm{mM} \mathrm{KCN} \mathrm{(d).} \mathrm{Symbols} \mathrm{are} \mathrm{as} \mathrm{in} \mathrm{(a)} \mathrm{and} \mathrm{the} \mathrm{bar} \mathrm{is} \mathrm{valid} \mathrm{for} \mathrm{(a)-(d).} \mathrm{(e)} \mathrm{Actively} \mathrm{gliding} \mathrm{filaments} \mathrm{of} F$. filiformis show nodes of the helically arranged 'band' (double arrow); at the apex the 'band' is wrapped around the pole (arrowhead) and the width of the 'band' is occasionally visible relative to the support plane, which has been tilted by $30^{\circ}$. ( $\mathrm{f}$ ) When the cells have been treated with $80 \mathrm{mM}$ sodium azide, the flattened appearance of gliding cells has changed to a smooth rod-like one. The filaments show a distinct septation (arrows) and large cytoplasmic gaps (encircled). Bar in (e) is valid for (f).

bacteria F. filiformis (strain Fxe1; DSMZ, Braunschweig, Germany) and F. johnsoniae (formerly C. johnsonae) (strain Cyj3; DSMZ, Braunschweig, Germany). Cells were grown as liquid cultures $(50 \mathrm{ml})$ in appropriate media at 320 r.p.m. on a rotary shaker at $30^{\circ} \mathrm{C}$. Mid-exponentially growing cells were collected by centrifugation at $5000-7000 \mathrm{~g}$ for $3 \mathrm{~min}$. Residual nutrient broth was thoroughly decanted from the cells, which were subsequently resuspended in $20 \mathrm{mM}$ HEPES, $\mathrm{pH} 7 \cdot 5$, in $1 / 5$ of the original culture volume. Fifty microlitres of the suspension was placed on cleaned cover-glasses $(15 \mathrm{~mm} \times 15$ $\mathrm{mm}$ ) and incubated for $3 \mathrm{~min}$ at ambient temperature. Cleaning of cover-glasses was done in $20 \%$ (v/v) aqueous
Mucasol (Merz) with ultrasound for $5 \mathrm{~min}$, followed by careful rinsing with tap water and finally with MilliQ reverse osmosis water. An aliquot of the cell suspension was checked by light microscopy to verify that the majority of cells were actively gliding, i.e. showed swarm formation, gliding trichomes or flexing movements, before they were processed further. In negative controls, gliding motility was stopped by addition of either $80 \mathrm{mM}$ aqueous sodium azide or $1 \mathrm{mM}$ $\mathrm{KCN}$, followed by incubation at ambient temperature for 3 min. Light microscopical examination showed that swarm formation or flexing activity immediately ceased when the respiratory inhibitors had been added. 

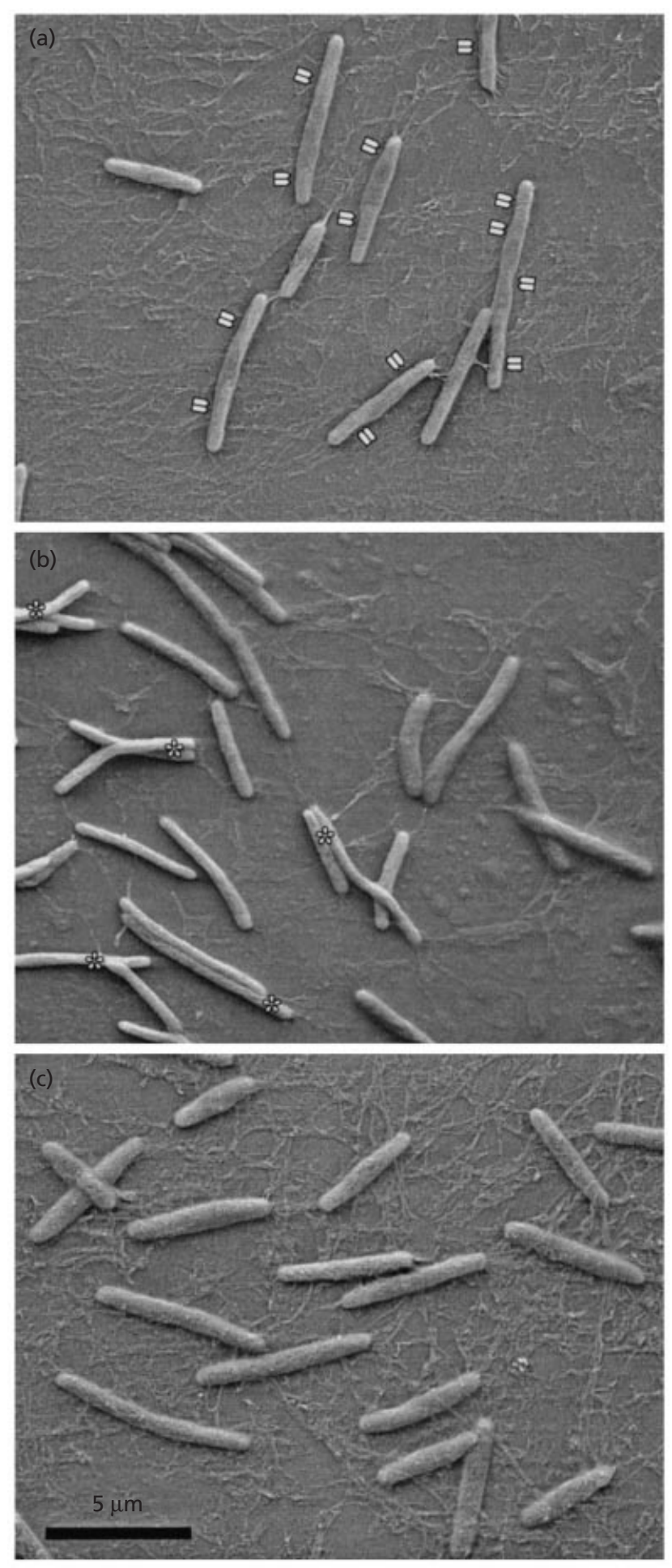

Fig. 2. Views of $M$. xanthus mutants. (a) Mutant DK10407, phenotype $A^{+} S^{-}$; twin arrows point to nodes of the continuous 'band'. (b) Mutant DK11303, phenotype $\mathrm{A}^{-} \mathrm{S}^{+}$; asterisks indicate cells which are not in firm contact with the substratum. (c) Mutant DK11316, phenotype $\mathrm{A}^{-} \mathrm{S}^{-}$.

Cryo-preparation and electron microscopy. Gliding motility as a dynamic state was fixed physically by shock freezing. In order to reduce the sample volume to a size optimal for freezing, cover-glasses were briefly spun off with the aid of a mini sawmill (Proxxon, Minimot 40). The cover-glass was fixed to double-adhesive tape, mounted on an aluminium stub used in scanning electron microscopy, and was plugged to the mini sawmill. After a $1 \mathrm{~s}$ run, the cover-glass was immediately dipped into melting nitrogen slush $\left(-210^{\circ} \mathrm{C}\right)$, taking care that air-drying was reduced to a minimum. After temperature equilibration the cover-glass with the shock-frozen cells was transferred into a storage vessel filled with liquid nitrogen. Samples were mounted to the stage of a freeze-drying facility (Baltec MED 020 unit) at a temperature of $-120^{\circ} \mathrm{C}$. Freezedrying was done in two steps at a sublimation pressure of 3 $\times 10^{-6}$ mbar: (a) $30 \mathrm{~min}$ at $-90^{\circ} \mathrm{C}$ and (b) $30 \mathrm{~min}$ at $-80^{\circ} \mathrm{C}$. The freeze-dried samples were subjected to shadow-casting at $90^{\circ}$ with platinum-carbon, and warmed to ambient temperature before they were withdrawn from the freeze-drying unit. The freeze-dried samples were stabilized by additional sputter coating with a $4 \mathrm{~nm}$ layer of gold (sample to target distance $50 \mathrm{~mm}$, sputter current $30 \mathrm{~mA}$, coating period $30 \mathrm{~s}$ ) in a sputter coater device SCD 040 from Balzers Union. Freezedried bacteria were examined in a DSM 982 Gemini scanning electron microscope equipped with a field emission gun (Zeiss). Micrographs were taken at a primary magnification from $\times 3000$ to $\times 20000$ at an acceleration voltage range from 0.5 to $10 \mathrm{kV}$ and a working distance from 4 to $5 \mathrm{~mm}$.

\section{RESULTS}

\section{Topography of the actively gliding versus the non-gliding state of bacterial cells}

The process of gliding motility of many unicellular and filamentous eubacteria has often been studied by light microscopy, and exact velocity measurements have been done by time-lapse recording (Reichenbach, 1980; Spormann \& Kaiser, 1995, 1999). Gliding motility of fruiting and non-fruiting bacteria, observed with the light microscope at maximum resolution, is recognized as a uniform translocation of cells along a surface. However, it has not been possible so far to reveal cellsurface-associated features directly related to this kind of movement by light microscopy. Prerequisites of ultrastructural analysis of the dynamic process of gliding motility by electron microscopy are (a) suitable fixation and stabilization, strictly free from artefacts during the preparative treatments, and (b) the majority of the bacterial population performs gliding motility. These points could be met by light microscopical observation of swarm formation and gliding motility of F. filiformis trichomes. The response on the addition of $80 \mathrm{mM}$ sodium azide or $1 \mathrm{mM} \mathrm{KCN}$, as potent inhibitors of the respiratory chain, to gliding cells was studied. It was found that gliding motility and flexing activity immediately stopped within $1-10 \mathrm{~s}$ after the addition of either one of the poisonous agents. Additional incubation for $3 \mathrm{~min}$ at room temperature ensured that gliding motility was completely stopped. Poisoned cells showed a characteristic smooth surface and septation of dividing cells was clearly seen (Fig. 1b, d, f). This appearance was clear cut and differed significantly from that of gliding bacteria which had not been treated with 

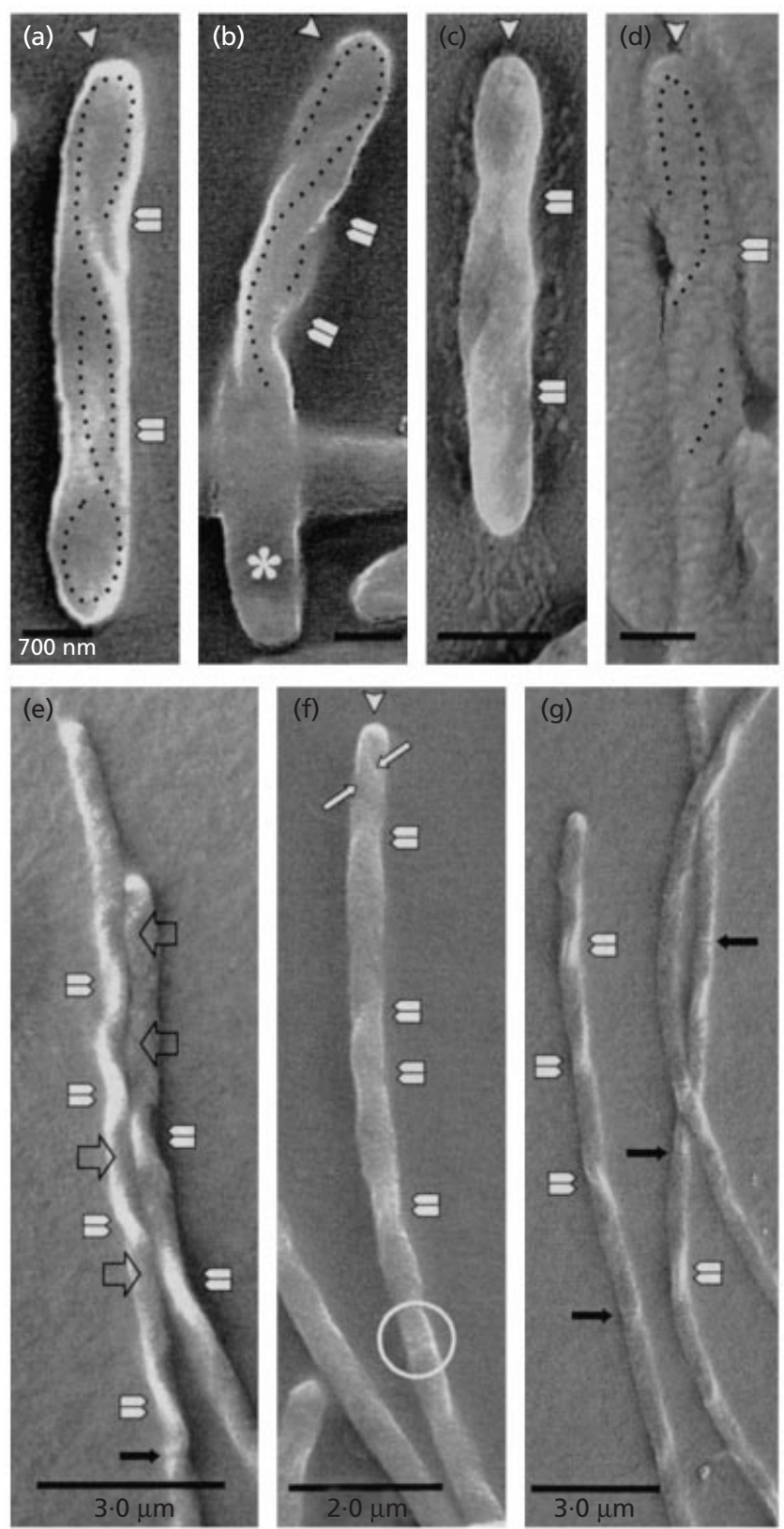

(h)

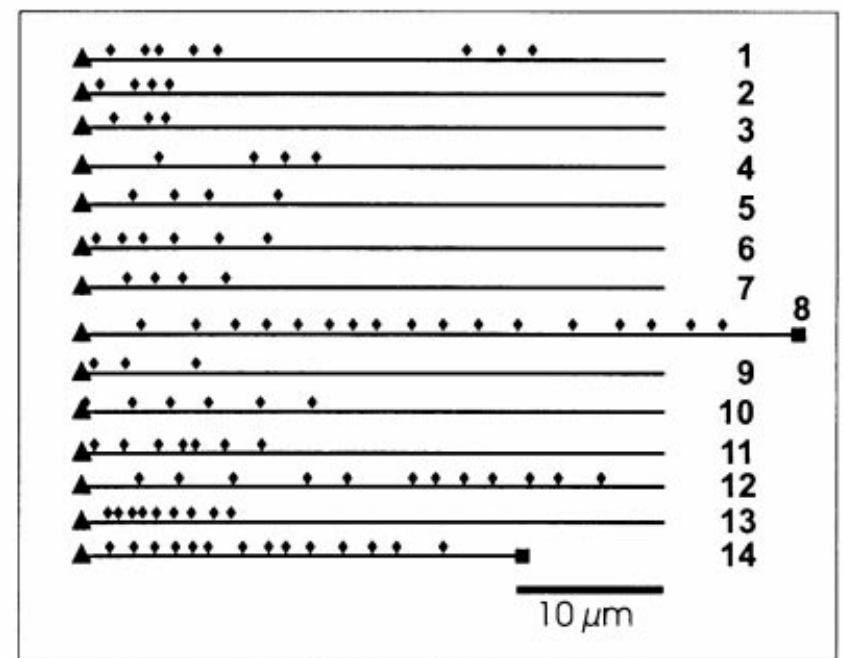

(i)

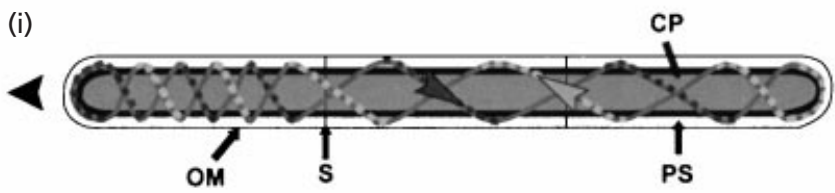

Fig. 3. Detailed view of the helical surface features of unicellular gliding bacteria. $(a, b)$ The band-like continuum of $M$. xanthus cells shows both anti-clockwise (a) and clockwise (b) polarity. Though the band-like continuum is outlined along the whole cell length (a), it is also possible that only the apical part of the 'band' is visible, while the distal part of the cell does not show helically arranged surface features (asterisk). Similarly, the band-like surface features of $S$. aurantiaca (c) and F. johnsoniae (d) can be seen. Arrowheads point to the 'band' that runs around the cell apex, and double arrows point to the nodes. Dotted lines $(a, b, d)$ indicate the path of the helical continuum. Dynamic surface features associated with the gliding state of $F$. filiformis are shown $(e, f, g)$. Double arrows $(e, f, g)$ indicate the positions of nodes along the filament, and black arrows $(e, g)$ point to septa. Opposing arrows ( $f$ ) indicate the 'band' width, and the arrowhead (f) points to the 'band' running around the apical end of the filament. The encircled part of the filament in ( $f$ ) shows a node crossing the septum of two adjacent cells. Open arrows in (e) indicate nodes aligned in register in filaments that are laterally in contact. (h) Schematic drawing of nodes clustered along $14 \mathrm{~F}$. filiformis filaments. The solid triangles on the left indicate the apical end of the filaments; diamond-shaped symbols indicate the internodal distances. The total size of filaments 8 and 14 is represented. (i) Model of the band-like helical circularly closed continuum of a filamentous glider, installed within the periplasmic space (PS). The internodal distances, as projected crossings of the continuous 'band', show narrow and wide spacings. The dotted parts along the 'band' indicate that part of the continuum that is visible from top, while those parts running at the bottom face of the filament in contact with the substratum are free from dots. The arrowheads mark the polarity of the continuous 'band' at the same plane of the filament. OM, outer membrane; CP, cytoplasm; S, septum; left arrowhead indicates the direction of gliding movement. Model not drawn to scale. 
azide or $\mathrm{KCN}$, and was similar to that of the rod-like, non-gliding bacteria Escherichia coli and Bacillus brevis, which were used as controls (data not shown). In particular, the multicellular filamentous gliding bacterium F. filiformis demonstrated distinct septation clefts between the protoplasts of a trichome (Fig. 1f, arrows).

In contrast to poisoned gliding bacteria and E. coli and $B$. brevis, actively gliding cells showed different topographies: they appeared flattened and folded. They showed a high variance of surface-associated morphological details, reflecting the intense modulation of motility-related components underneath the cell surface (Fig. 1a, c, e). Strikingly, they showed a helically arranged surface fold or 'band' running along the bacterial cell. This 'band' is structurally equivalent to the 'belt' described by Lünsdorf \& Reichenbach (1989). Similar features were observed in gliding mutants, phenotype $\mathrm{A}^{+} \mathrm{S}^{-}$, of $M$. xanthus, whereas mutants of phenotypes $\mathrm{A}^{-} \mathrm{S}^{+}$and $\mathrm{A}^{-} \mathrm{S}^{-}$and a $m g l$ mutant (data not shown) did not show the helical surface 'band' (Fig. 2). This 'band' changed its direction after it passed the cell apex (see arrowheads in Fig. 1a, c, e, Fig. 3a, b, c, d), and a distinct polarity of the helical 'band', either lefthanded or right-handed, was observed with different cells of the same species, as can be recognized for $M$. xanthus (Fig. 3a, b). At suitably oriented positions, the width of the 'band' could be topographically discriminated (Fig. 1a, c, e: opposing arrows). Measurements of width were done normally to the 'band' and for M. xanthus the width ranged from 250 to $380 \mathrm{~nm}$. For S. aurantiaca the range was $170-300 \mathrm{~nm}$, F. filiformis had a width range from 200 to $330 \mathrm{~nm}$, and the $F$. johnsoniae 'band' width ranged from 210 to $290 \mathrm{~nm}$.

A further structural detail of the continous 'band' is indicative of and common to all gliding bacteria analysed in the present work. It is the occurrence of 'nodes', which represent intersections of the continuous 'band' along the cell body (Fig. 1a, c, e, Fig. 2a, Fig. 3a-e: twin arrows). Two internodal distances, i.e. the spacing between three nodes, define the wavelength $\lambda$ of the 'band' and as such represent one helical turn. Short cells of M. xanthus which had a diameter of $680 \mathrm{~nm}$ showed a wavelength $\lambda$ of $3 \mu \mathrm{m}$, whereas $S$. aurantiaca, $570 \mathrm{~nm}$ in diameter, had a wavelength $\lambda$ between 2.3 and $2.7 \mu \mathrm{m}$. In the case of $M$. xanthus, the number of helical turns per cell ranged from 1.0 to 1.5 or even higher and appeared to be correlated with the individual cell length.

In general, by following the traits of the helical folds, the ' in toto' topography of this dynamic state can be described as a circularly closed band-shaped continuum which is twisted along the longitudinal axis of the cell. The proximal end of a cell may present the active helical principle and the distal part of the cell body appears smooth, as can be recognized from Fig. 3(b) (asterisk). This interruption of continuous helicity may be indicative of an only partially active gliding machinery or even different states of gliding activity.

\section{Morphological evidence of the progression of gliding force vectors and surface dynamics}

The question arises of how the translational force vectors that drive the cell ahead are established. Do they just follow the traces of an either left- or right-handed rotating spiral driller as a rigid construction with a constant wavelength, i.e. equidistant nodes, or are they based on an apparatus which in its overall complexity produces varying internodal distances at variable wavelengths? The latter mode would imply that gliding motility is based on oscillation of the twisted closed continuum.

Here, the filamentous form of F. filiformis was a suitable multicellular system to test and elaborate these details. In Fig. 1(e) and Fig. 3(e, f, g) (twin arrowheads), several nodes at varying distances can be observed along the filaments. Nodes do not appear to be restricted to individual cells within the trichome but uniformly cross the intercellular septum (Fig. 3f, circle). If two trichomes contact each other and are oriented lengthwise, their helical nodes appear aligned in phase, thus giving evidence for synchronization (Fig. 3e, open arrows). A schematic presentation of internodal distances relative to the cell's apex is outlined in Fig. 3(h), encompassing 14 individual filaments. The mean value of 101 internodal distances of F. filiformis trichomes was found to be $2.27 \mu \mathrm{m} \pm 1.09 \mu \mathrm{m}$. The overall wavelength $\lambda$ is $5.54 \mu \mathrm{m}$ as a mean and minimally $2.36 \mu \mathrm{m}$ versus maximally $6.72 \mu \mathrm{m}$. The standard deviation of $1.09 \mu \mathrm{m}$ underlines the great variance of the internodal distances. This characterizes the underlying apparatus as flexible rather than rigid in nature. Further, the distribution of nodes along the filaments indicates that they are mainly found at the apex (see filaments 2, 3, 6, 9, 10, 11 and 13 in Fig. 3h), though nodes appear further downwards, separated by a region free of intersections (Fig. 3h, filament 1). However, the apex is not the only region presenting nodes. This disproves the assumption that gliding activities along the filament were restricted to its leading edge. Nodes were found scattered generally along the whole filament (see Fig. 3h, filaments 8, 12 and 14).

In general, the distribution of nodes along the filaments thus strongly implies gliding activity to be based on oscillating translational force vectors, as is outlined in a model (Fig. 3i).

\section{DISCUSSION}

The macromolecular basis of bacterial gliding motility is still enigmatic. Insufficient resolution power is obtained by conventional light microscopy to observe the far submicron details that represent features of the actual gliding process. Until now, insights into the mode of action of gliding motility have been attempted to be obtained by the observation of latex beads that move along and around gliding cells (Pate \& Chang, 1979; Lapidus \& Berg, 1982; Ridgway \& Lewin, 1988; Beatson \& Marshall, 1994). It has been argued that the 
observed patterns of bead movement are directly correlated with the gliding process and its underlying molecular machinery (Lapidus \& Berg, 1982). However, Ridgway \& Lewin (1988) and Gorski et al. (1991) have contradicted this strict association. They demonstrated gliding motility and bead movement to be independent. From the beginning of investigations on the gliding mechanism, it has been attempted, by high-resolution electron microscopy, to obtain insights into the gliding process and to find some mechanical solutions that could help to understand this phenomenon of translocational activity. Based on their observations, Humphrey et al. (1979) postulated rhythmical contractions of the outer membrane that might originate from make-and-break interactions of the gliding machinery between the rigid murein layer and the outer membrane. The generation of wave patterns was observed and they have been supposed to be established on a potential difference along the cell's axis, which was assumed to be initiated by an apical proton port (Harold, 1977). A similar wavy pattern was found with conventional freeze-fractured or embedded Flexibacter and Cytophaga cells. It was proposed to originate from the undulating outer membrane (Beatson \& Marshall, 1994; Dickson et al., 1980). However, one may argue that these waves are impaired by osmotic effects, since osmotically active glycerol was used as a cryoprotectant at a final concentration of $10 \%$ (Dickson et al., 1980). This may result in irregular shrinkage of the surface, producing some wavy longitudinal as well as transverse folds. Similarly, freeze-etched cells, shock-frozen without a cryoprotectant, showed a smooth cell surface (Beatson \& Marshall, 1994). An osmotic sensitivity of some gliding bacteria seems to be obvious. Negatively stained cells of Myxococcus fulvus showed distinct longitudinal folds in the presence of aqueous $4 \%$ uranyl acetate, whereas no such folds could be observed in the presence of $1.5 \%$ uranyl acetate (Lünsdorf \& Reichenbach, 1989). Similar osmotically generated shrinking artefacts are observed in glutaraldehyde-buffered fixatives (Mathieu et al., 1978).

To minimize the shortcomings mentioned above, our rationale led us to halt and fix gliding motility of four different bacterial species, i.e. M.xanthus, S. aurantiaca, $F$. filiformis and F. johnsoniae, by shock freezing under optimal vitrifying conditions in melting nitrogen at $-210{ }^{\circ} \mathrm{C}$ without the addition of cryoprotectants. This is a prerequisite to maintaining the dynamic states of surface features of actively gliding cells, since these are highly sensitive and respond immediately to alterations of the surrounding milieu.

To differentiate gliding-associated surface patterns from those of non-gliding cells it was necessary to arrest gliding motility as a control. This was achieved effectively by using cyanide and azide as potent inhibitors of electron transport (Ridgway, 1977): these are weak proton ionophores and cause a partial breakdown of the membrane potential (Harold, 1972, 1977; Duxburry et al., 1980; Dzink-Fox et al., 1997). Our data show for the first time the obvious impact of electron flow inhibition on surface features of actively gliding cells. These cells appear as rods with a smooth surface and, furthermore, the close contact of adjacent cells within filaments is no longer observed (Fig. 1b, d). This may represent the morphological counterpart of impaired cell cohesion, which was found to be energy-dependent in myxobacteria (Gilmore \& White, 1985; Shimkets, 1986).

Actively gliding cells show a distinct surface pattern that is obviously created by macromolecular structures which are organized ' in toto' as a supertwisted circularly closed 'band'. A clearly helically arranged surface pattern at the end of a cell from M. fulvus assumed to be actively gliding has been described in negatively stained specimens. However, this pattern faded away further down the cell and no data on the helix pitch were obtained (Lünsdorf \& Reichenbach, 1989). So-called 'strands', composed of 'rings' and 'elongated elements', were described as fragments from mechanically broken cells and they were shown to end up in a so-called 'belt', about $300 \mathrm{~nm}$ in width, which was wrapped around the cell. Similar 'strands' were found in M. xanthus (Freese et al., 1997). It is assumed that by conformational changes of 'rings' relative towards the 'elongated elements' along the 'strands' of the 'belt', gliding motility of M. fulvus is performed. The present study substantiates the existence of a 'belt' that represents the morphological equivalent of the circularly closed 'bands' seen in relief (Fig. 3i). It is observed in all gliding cells examined in the present study and shows a width of 170-380 nm. We suppose these circularly closed 'bands' or 'belts' to be directly associated with the peripheral part of the gliding machinery within the periplasmic space. So-called 'strands', as integral parts of the 'belt', were found to be situated within the periplasmic space and in direct contact with the outer membrane, as was shown by 'in situ' freeze-fracture studies of M. fulvus (Freese et al., 1997). This is consistent with the helicity, inferred from light microscopical studies of movement patterns of latex beads and ink particles of cytophagas and flexibacters (Lapidus \& Berg, 1982; Ridgway \& Lewin, 1988; Beatson \& Marshall, 1994) or the appearance of slime threads that are helically wrapped around gliding filaments (Reichenbach, 1980; Halfen \& Castenholz, 1970). These observations fit the presented ultrastructural data of dynamic states of actively gliding cells.

The ultrastructural appearance of unicellular and filamentous gliding bacteria gives an impression of the flexibility of the supertwisted gliding apparatus as a circularly closed continuum, and some general considerations can be made.

(1) The helical pitches from different cells of the same species vary to a certain degree, inferring that gliding is an individual cell process and not strictly synchronized, on the assumption that single cells are not moving in rafts (Fig. 1a, b). One may speculate whether, relative to the degree of gliding intensity of a single cell, the profile of the cell's surface is accordingly modulated. Since the 
observed cells were all prepared from liquid cultures and were brought into contact with the substratum for only a few minutes, all cells were in the 'Such'-situation, i.e. were coordinating and arranging one another before building the gliding swarm. Furthermore, it has to be considered that cells are continuously pressed against the substratum by surface tension during drying of the surrounding liquid. Such flattening has been observed by phase-contrast light microscopy of $F$. filiformis trichomes as a change in cell width from thin in liquidsaturated surroundings to broad in liquid-deficient surroundings (data not shown). As a consequence of this situation, the topographic profile of the cell surface changed from pronounced to smooth. Therefore, care was taken to analyse only those areas with actively gliding cells that were completely covered with a thin liquid layer immediately before shock freezing. Thus alterations of gliding-associated surface features by surface tension were prevented.

(2) It is obvious from gliding trichomes of F. filiformis that the gliding motility process is often restricted to different parts of the filament, as is outlined by the distribution of helical nodes (Fig. 3h). This demonstrates a gliding correlated alteration of the wavelengths and consequently of the helical pitches along an individual trichome. It seems obvious that a group of equidistant nodes may move along the trichome during gliding similar to travelling waves. In accordance with this impression, nodes appear to cross the septa without being split during transition (Fig. 3f). It seems plausible that the nodes of the travelling waves may correlate with the dark adhesion zones that have been described by Godwin et al. (1989) from interference reflection microscopic studies and time-lapse video recording. Furthermore, if two adhesion zones or focal contacts of a trichome or single cell have different translational speeds relative to one another, the interspatial non-adhesive part of the trichome will equilibrate the growing imbalance of tension by bending out and forming a curved trichome, which often could be observed with $F$. filiformis. If both adhesion zones move with the same speed, the curvature of the trichome will be maintained. In this state, the trichome will glide forward as long as the speed synchronization is maintained and force vectors of both adhesive zones run strictly in parallel. In this way, the diverse curvilinear features of gliding cells, as have been described for M. xanthus (Spormann \& Kaiser, 1995) and cyanobacterial trichomes of Phormidium uncinatum (Häder \& Vogel, 1991) by timelapse video, could be explained.

(3) The nodes of the supertwisted continuous 'band' may act as physical points in cell alignment, useful for synchronization of the gliding process of several cells laterally in contact (Fig. 3e, open arrows).

(4) The irregular distribution of nodes along the trichomes implies that different motility speeds, possibly correlated with appropriate frequencies, may influence and alter the pitch height.
(5) The presence of right- and left-handed helicity of the continuous 'band' (Fig. 3a, b) may be linked to forwards and/or backwards movements of the cells.

(6) The observed nodes of the actively gliding wild-type cells of M. xanthus are obviously under the regime of the adventurous multigene system (Hodgkin \& Kaiser, $1979 \mathrm{a}, \mathrm{b})$, since they are only present in $\mathrm{A}^{+} \mathrm{S}^{-}$mutants (Fig. 2a) and not in $\mathrm{A}^{-} \mathrm{S}^{+}$(Fig. 2b) or $\mathrm{A}^{-} \mathrm{S}^{-}$(Fig. 2c) mutants and a $m g l$ mutant.

One main feature of the supertwisted circularly closed continuum is its anti-parallelism, as indicated in the model (Fig. 3i, arrowheads). If one assumes the gliding apparatus to move helically along the cell body within the periplasmic space, the force vectors are oppositely oriented. If the adhesive zones of these force vectors have the same intensity of contact with the substratum, the translocating forces will neutralize each other and no net movement will occur. Ridgway \& Lewin (1988) have already mentioned this problem. A simple solution is to postulate an uncoupling of those adhesive zones from the substratum which are oppositely oriented to the direction of cell locomotion. Weak support for this suggestion is obvious from interference reflection microscopy (Godwin et al., 1989). Here, the bright-shining parts of gliding cells that are not in contact with the substratum represent those regions of oppositely directed force vectors and thus do not hinder forward translocation. However, these different adhesion intensities of cells with the substratum imply a rather complex regulation and coordination of the gliding machinery, and in consequence demand a force sensing capability, which still has to be verified.

The high-resolution data presented, obtained from four different species of gliding bacteria and an $\mathrm{A}^{+} \mathrm{S}^{-}$gliding mutant of $M$. xanthus, for the first time give strong evidence of the 'in toto' topographic appearance of the gliding machinery in action upon freezing the various states of this complex, dynamic motility process. However, its design at the macromolecular level could not be elucidated and high-resolution electron microscopy data at this level remain fragmentary (Pate \& Chang, 1979; Lünsdorf \& Reichenbach, 1989; Freese et al., 1997). In particular, the question of how the gliding machinery is organized at the septa of filamentous gliding bacteria is enigmatic. Nevertheless, all these morphological data are of value as pieces in this mosaic, termed 'bacterial gliding motility'.

\section{ACKNOWLEDGEMENTS}

We thank Dr D. Kaiser (Department of Biochemistry and Developmental Biology, Stanford University) for making $M$. xanthus DK1622, DK10407, DK11303, DK11316 and DK6204 available to us. We thank Dr H. Reichenbach (GBF, Department of Biology of Natural Products, Braunschweig) for his continuous interest and support of the present work, especially for his gift of F. filiformis. The experienced 
assistance of Elke Haase (GBF, Braunschweig) on performing the cryoelectron microscopic preparations is gratefully acknowledged. Finally, we thank Dr E. Moore (GBF, Braunschweig) for reading the manuscript.

\section{REFERENCES}

Abbanat, D. R., Leadbetter, E. R., Godchaux, W., III \& Escher, A. (1986). Sulphonolipids are molecular determinants of gliding motility. Nature 324, 367-369.

Beatson, P. J. \& Marshall, K. C. (1994). A proposed helical mechanism for gliding motility in three gliding bacteria (order Cytophagales). Can J Microbiol 40, 173-183.

Burchard, R. P. (1981). Gliding motility of prokaryotes: ultrastructure, physiology, and genetics. Annu Rev Microbiol 35, 497-529.

Burchard, R. P. (1984). Gliding motility and taxes. In The Myxobacteria, pp. 139-161. Edited by E. Rosenberg. Berlin \& Heidelberg: Springer.

Burchard, A. C., Burchard, R. P. \& Kloetzel, J. A. (1977). Intracellular, periodic structures in the gliding bacterium Myxococcus xanthus. J Bacteriol 132, 666-672.

Castenholz, R. W. (1982). Motility and taxes. In The Biology of Cyanobacteria, pp. 413-439. Edited by N. G. Carr \& B. A. Whitton. Oxford: Blackwell Scientific Publications.

Dickson, M. R., Kouprach, S., Humphrey, B. A. \& Marshall, K. C. (1980). Does gliding motility depend on undulating membranes? Micron 11, 381-382.

Duxburry, T., Humphrey, B. A. \& Marshall, K. C. (1980). Continuous observations of bacterial gliding motility in a dialysis microchamber: the effects of inhibitors. Arch Microbiol 124, 169-175.

Dworkin, M. (1996). Recent advances in the social and developmental biology of myxobacteria. Microbiol Rev 60, 70-102.

Dzink-Fox, J. L., Leadbetter, E. R. \& Godchaux, W., III (1997). Acetate acts as a protonophore and differentially affects bead movement and cell migration of the gliding bacterium Cytophaga johnsonae (Flavobacterium johnsoniae). Microbiology 143, 3693-3701.

Freese, A., Reichenbach, H. \& Lünsdorf, H. (1997). Further characterization and in situ localization of chain-like aggregates of the gliding bacteria Myxococcus fulvus and Myxococcus xanthus. J Bacteriol 179, 1246-1252.

Gilmore, D. F. \& White, D. (1985). Energy-dependent cell cohesion in myxobacteria. J Bacteriol 161, 113-117.

Godwin, S. L., Fletcher, M. \& Burchard, R. T. (1989). Interference reflection microscopic study of sites of association between gliding bacteria and glass substrata. J Bacteriol 171, 4589-4594.

Gorski, L., Leadbetter, E. R. \& Godchaux, W., III (1991). Temporal sequence of trait recovery during phenotypic curing of a Cytophaga johnsonae motility mutant. J Bacteriol 173, 7534-7539.

Gorski, L., Godchaux, W., III, Leadbetter, E. R. \& Wagner, R. R. (1992). Diversity in surface features of Cytophaga johnsonae motility mutants. J Gen Microbiol 138, 1767-1772.

Gorski, L., Godchaux, W., III \& Leadbetter, E. R. (1993). Structural specificity of sugars that inhibit gliding motility of Cytophaga johnsonae. Arch Microbiol 160, 121-125.

Häder, D. P. \& Vogel, K. (1991). Interactive image analysis system to determine the motility and velocity of cyanobacterial filaments. J Biochem Biophys Methods 22, 289-300.

Halfen, L. N. \& Castenholz, R. W. (1970). Gliding in a blue-green alga: a possible mechanism. Nature 225, 1163-1164.

Harold, F. M. (1972). Conservation and transformation of energy in bacterial membranes. Bacteriol Rev 36, 172-230.

Harold, F. M. (1977). Ion currents and physiological functions in microorganisms. Annu Rev Microbiol 31, 181-203.

Hartzell, P. \& Kaiser, D. (1991). Upstream gene of the mgl operon controls the level of MglA protein in Myxococcus xanthus. J Bacteriol 173, 7625-7635.

Hodgkin, J. \& Kaiser, D. (1979a). Genetics of gliding motility in Myxococcus xanthus (Myxobacterales) : genes controlling movement of single cells. Mol Gen Genet 171, 167-176.

Hodgkin, J. \& Kaiser, D. (1979b). Genetics of gliding motility in Myxococcus xanthus (Myxobacterales): two gene systems control movement. Mol Gen Genet 171, 177-191.

Humphrey, B. A., Dickson, M. R. \& Marshall, K. C. (1979). Physicochemical and in situ observations on the adhesion of gliding bacteria to surfaces. Arch Microbiol 120, 231-238.

Keller, K. H., Grady, N. \& Dworkin, M. (1983). Surface tension gradients: feasible model for gliding motility of Myxococcus xanthus. J Bacteriol 155, 1358-1366.

Lapidus, I. R. \& Berg, H. C. (1982). Gliding motility of Cytophaga sp. strain U67. J Bacteriol 151, 384-398.

Lünsdorf, H. \& Reichenbach, H. (1989). Ultrastructural details of the apparatus of gliding motility of Myxococcus fulvus (Мyxobacterales). J Gen Microbiol 135, 1633-1641.

Mathieu, O., Claassen, H. \& Weibel, E. R. (1978). Differential effect of glutaraldehyde and buffer osmolarity on cell dimensions: a study on lung tissue. J Ultrastruct Res 63, 20-24.

Pate, J. L. (1988). Gliding motility in procaryotic cells. Can J Microbiol 34, 459-465.

Pate, J. L. \& Chang, L.-Y. E. (1979). Evidence that gliding motility in procaryotic cells is driven by rotary assemblies in the cell envelopes. Curr Microbiol 2, 59-64.

Qualls, G. T., Stephens, K. \& White, D. (1978). Morphogenetic movements and multicellular development in the fruiting myxobacterium Stigmatella aurantiaca. Dev Biol 66, 270-274.

Reichenbach, H. (1980). Saprospira grandis (Leucotrichales) Wachstum und Bewegung. Film E 2424 des IWF, Göttingen. Sekt Biol, Ser. 13, Nr. 26/E 2424, 1-21.

Ridgway, H. (1977). Source of energy for gliding motility in Flexibacter polymorphus: effects of metabolic and respiratory inhibitors on gliding movement. J Bacteriol 131, 544-556.

Ridgway, H. F. \& Lewin, R. A. (1988). Characterization of gliding motility in Flexibacter polymorphus. Cell Motil Cytoskelet 11, 46-63.

Shimkets, L. J. (1986). Correlation of energy-dependent cell cohesion with social motility in Myxococcus xanthus. J Bacteriol 166, 837-841.

Spormann, A. M. (1999). Gliding motility in bacteria: insights from studies of Myxococcus xanthus. Microbiol Mol Biol Rev 63, 621-641.

Spormann, A. M. \& Kaiser, A. D. (1995). Gliding movements in Myxococcus xanthus. J Bacteriol 177, 5846-5852.

Spormann, A. M. \& Kaiser, D. (1999). Gliding mutants of Myxococcus xanthus with high reversal frequencies and small displacements. J Bacteriol 181, 2593-2601. 
Stackebrandt, E. (1985). Phylogeny and phylogenetic classification of procaryotes. In Evolution of Procaryotes, pp. 309-334. Edited by K. H. Schleifer \& E. Stackebrandt. FEMS Symposium 29. London: Academic Press.

Sutherland, I. W. (1979). Polysaccharides produced by Cystobacter, Archangium, Sorangium and Stigmatella species. J Gen Microbiol 111, 211-216.
Sutherland, I. W. \& Thomson, S. (1975). Comparison of polysaccharides produced by Myxococcus strains. J Gen Microbiol 89, 124-132.

Received 2 August 2000; revised 6 December 2000; accepted 11 December 2000. 